специальности 032400 «Биология». М.: Гуманитар. изд. центр «Владос», 2005. 463 с.

11. Сибиркина А.Р. Биогеохимическая оценка содержания тяжелых металлов в сосновых борах Семипалатинского Прииртышья: автореф. дис. ... д-ра биол. наук: 03.02.08. Омск, 2014. 37 с.

12. Физиология растений: конспект лекций / В.М. Гольд, Н.А. Гаевский, Т.И. Голованова и др. Красноярск: ИПК СФУ, 2008.

13. Стовба Я.В. Оценка возможности фитоочистки сточных вод от ионов тяжелых металлов // Международная научная конференция MicroCAD: Секція № 18: Нові технології захисту навколишнього середовища та утилізації відходів. Харьков: ХПИ, 2010.

14. Словарь терминов и понятий по физиологии и биохимии растений: уч. пособие. М.: РГАУ - МСХА им. К.А. Тимирязева. 2007. 100 с.

15. Курсанов А.Л. Транспорт ассимилятов в растении. М.: Наука, 1999. 648 с.
16. Заводская О.Ф., Копнина А.Ю. Очистка воды, загрязненной различными компонентами, с помощью урути мутовчатой // Известия Самарского научного центра Российской академии наук. 2013. Т. 15, № 3-6. С. 1771-1774.

17. Доклад об экологической ситуации в Самарской области за 2017 год. Выпуск 27. Самара, 2017. $228 \mathrm{c}$.

18. ГОСТ 4388-72. Вода питьевая. Методы определения массовой концентрации меди. М.: ФГУП «Стандартинформ», 2010.

19. Петренко Е.Н., Галдеева О.Ф., Копнина А.Ю. Извлечение ценных компонентов из биомассы высших водных растений, образующейся в процессе фиторемедиации // Биотические компоненты экосистем: сборник трудов научного симпозиума. Самара, 2017. С. $105-109$.

\title{
ECOLOGICAL ASPECTS OF HEAVY METALS ACCUMULATION IN HIGHER AQUATIC PLANTS IN THE PROCESS OF PHYTOREMEDIATION
}

(C) 2018

Galdeeva Olga Fedorovna, assistant of Chemical Technology and Industrial Ecology Department

Kozlovskaya Olga Viktorovna, candidate of biological sciences, associate professor of Chemical Technology and Industrial Ecology Department

Kopnina Alina Yurievna, candidate of chemical sciences, associate professor of Chemical Technology and Industrial Ecology Department Samara State Technical University (Samara, Russian Federation)

\footnotetext{
Abstract. This paper deals with pollution of natural and waste waters with heavy metals in the conditions of technogenic impact. It describes one of the numerous methods for neutralizing various contaminants in the aquatic environment, in particular phytoremediation, which has been used for more than 50 years in various countries. The paper considers the role of higher aquatic plants which, according to a variety of confirmatory studies, can be used to extract toxic components from natural and waste water - heavy metal ions. The authors consider a possibility of inorganic origin pollutants extraction with the help of higher water plants of Myriophyllum verticillatum L. and Elodea canadensis Michx. in laboratory conditions. The authors determined pollutants concentration change dependence in the solution with a process duration of less than 10 hours. The authors proved that the maximum purification efficiency is achieved only with the combined use of higher aquatic plants and perfetron. The results of the studies indicate a possibility of water purification from heavy metal ions (ferric iron, bivalent copper, bichromate ions) with the help of higher water plants Myriophyllum verticillatum L. and Elodea canadensis Michx.

Keywords: phytotechnology; phytoremediation; extraction; heavy metals; pollutants; maximum permissible concentration; phytophagous; periphyton; cleaning efficiency; intracellular accumulation; tolerance of plants; Myriophyllum verticillatum L.; Elodea canadensis Michx; turgor; osmotic pressure; waste; Samara city; Samara Region.
}

УДК 502.5 (204)

Статья поступила в редакцию 16.04.2018

\section{ЭКОЛОГИЧЕСКИЙ МОНИТОРИНГ ЕРИКА СУДОМОЙКА ВОЛГО-АХТУБИНСКОЙ ПОЙМЫ} (C) 2018

Герман Надежда Валерьевна, кандидат биологических наук, доцент кафедры экологии и природопользования

Бабичева Алина Валентиновна, студент института естественных наук

Манаенков Игорь Викторович, кандидат биологических наук, доцент кафедры экологии и природопользования

Волгоградский государственный университет (2. Волгоград, Российская Федерация)

Севрюкова Галина Александровна, доктор биологических наук, доцент,

профессор кафедры промышленной экологии и безопасности жизнедеятельности

Волгоградский государственный технический университет (г. Волгоград, Российская Федерация)

Аннотащия. Работа посвящена экологическому мониторингу и системному анализу водоема Волгоградской области (ерик Судомойка). Экологический мониторинг проводился с марта 2017 года по февраль 2018 года. В комплекс исследований входило: определение органолептических показателей воды, количества растворенного кислорода в водоеме, водородного показателя, сухого остатка и биоиндикация. Установлено увеличение количества микроорганизмов: синедры (Synedra), спирогиры (Spirogyra), мужоции (Mougeotia), 
Герман Н.В., Бабичева А.В., Манаенков И.В., Севрюкова Г.А.

Экологический мониторинг ерика Судомойка Волго-Ахтубинской поймы..

03.02.00 - общая биология

которые являются биоиндикаторами качества воды, - в июле, сентябре 2017 г. и в феврале 2018 г. Наличие высокого количества микроорганизмов-биоиндикаторов свидетельствует о перенасыщении воды кислородом и образовании органических веществ. Выявлено повышение минерализации воды в марте, июле, декабре 2017 г., феврале 2018 г. В пробах воды ерика Судомойка в зимний период обнаружено большое количество слизи, яйцекладок различных насекомых, органической грязи, что свидетельствует о загрязнении водоема в зимний период. Качество воды в ерике Судомойка неудовлетворительное, ерик классифицируется как слабозагрязненный водоем. Ерик Судомойка не может быть использован в бытовых целях жителями близлежащих населенных пунктов и является неблагоприятным для купания в летний период. Экологическое состояние ерика Судомойки обусловливает экологическое состояние всего природного комплекса Волго-Ахтубинской поймы.

Ключевые слова: Волгоградская область; Волго-Ахтубинская пойма; ерик Судомойка; природный парк; экологический мониторинг; системный анализ; загрязнение; минерализация воды; водородный показатель; биоиндикация; синедра (Synedra); спирогира (Spirogyra); мужоция (Mougeotia).

\section{Введение}

Экологическая проблема ухудшения состояния водоемов, протекающих вблизи как крупных, так и небольших городов в настоящее время является одной из актуальных. На территории Волгоградской области вблизи г. Краснослободска Среднеахтубинского района, на верхнем участке Волго-Ахтубинской поймы, протекает небольшой ерик под названием Судомойка, протяженностью около 5 км. По берегам водоема располагаются дачные массивы, небольшая часть микрорайона города Краснослободска и другие поселения. Достаточно большое количество населенных пунктов, находящихся по обе стороны от вод ерика, оказывают антропогенное влияние на экологическое состояние водоема. Ввиду того, что вода из водоема используется в большом количестве на сельскохозяйственные нужды, а также для обеспечения основного водного питания Волго-Ахтубинской поймы [1, с. $21 ; 2$, с. 105], нами было принято решение о проведении экологического мониторинга данного водоема в течение 2017 года.

Целью данной работы явилось проведение экологического мониторинга и системного анализа исследуемого водоема (ерик Судомойка) для определения возможности употребления воды для полива сельхозугодий, бытовых нужд, а также ее пригодности для купания в летний период.

\section{Объекты и методы исследований}

Экологический мониторинг проводился с марта 2017 года по февраль 2018 года с определенной периодичностью. В комплекс исследований были включены методики определения органолептических показателей воды, количества растворенного кислорода в водоеме с помощью мобильного оборудования (анализатор растворенного кислорода МАРК 302Э), водородного показателя с помощью $\mathrm{pH}$-метра 150 , сухого остатка и метод биоиндикации.
Для определения степени минерализации воды в водоеме была выбрана методика «определения сухого остатка», т.к. она наиболее универсальна. Для эксперимента требуется стандартное оборудование: баня паровая водный термостат (DZKW на 6 мест), сухожаровой шкаф (ШС-80-01-СПУ), аналитические весы (ATX/ATY Shimadzu), фарфоровые чашки, мерная и лабораторная посуда общего назначения. Перед началом эксперимента фарфоровую чашку помещали в сухожаровой шкаф на 2 ч., после остывания взвешивали. Параллельно с этим исследуемую воду фильтровали, в количестве 250 мл наливали в фарфоровую чашку и выпаривали на водяной бане. После этого ее вновь помещали в сухожаровой шкаф еще на 2 ч. Расчеты проводили по формуле:

$$
x=\frac{(m-m 1) \times 100 c}{V},
$$

где $\mathrm{x}$ - количество сухого остатка (мг/дм³), m - масса емкости с сухим остатком, мг; $\mathrm{m} 1$ - масса пустой емкости, мг; V - количество воды, взятой для эксперимента, см$^{3}[3$, с. 10-11; 4, с. 110].

\section{Результаты исследований и их обсуждение}

По данным результатов биологического метода исследования нами были обнаружены микроорганизмы, служащие биоиндикаторами качества воды (табл. 1). Следует отметить, что при наличии в водоеме органических веществ водоросли могут сменить свой основной тип питания, осуществляемый с помощью фотосинтеза на фоторедукционный, фотогетеротрофный, автогетеротрофный, гетероавтотрофный и даже на полный гетеротрофный тип питания. Использование органических веществ в качестве дополнительного источника питания, а также способность к смешанному типу питания обусловливают рост их биомассы [5, с. 839$]$.

Таблица 1 - Динамика количественного и качественного содержания микроорганизмов-биоиндикаторов в исследуемом водоеме (ерик Судомойка)

\begin{tabular}{|l|c|c|c|c|c|c|c|}
\hline \multirow{2}{*}{\multicolumn{1}{c|}{ Виды организмов }} & \multicolumn{7}{c|}{ Количество микроорганизмов } \\
\cline { 2 - 9 } & 03.2017 & 04.2017 & 05.2017 & 07.2017 & 09.2017 & 12.2017 & 02.2018 \\
\hline Нитцшия игловидная (Nitzschia) & 7 & 13 & - & 16 & - & 2 & - \\
\hline Синедра (Synedra) & 13 & 10 & 9 & 20 & 17 & - & 8 \\
\hline Зеленая одноклеточная (Chlorophyta) & 1 & - & 1 & - & - & - & - \\
\hline Кладорфа (Cladophora) & 1 & - & - & - & - & - & - \\
\hline Циклоп (Cусlopidae) & 2 & 1 & - & 6 & 3 & - & - \\
\hline Спирогира (Spirogyra) & - & 15 & 9 & 25 & 27 & 5 & 10 \\
\hline Мужоция (Mougeotia) & - & - & 2 & 6 & - & - & - \\
\hline Род Гимнозига (Gymnozyga) & - & - & 3 & 9 & - & - & - \\
\hline
\end{tabular}


Герман Н.В., Бабичева А.В., Манаенков И.В., Севрюкова Г.А.

Продуктивность и урожайность микроскопических водорослей зависит от концентрации питательных веществ в окружающей среде. Из минеральных веществ водорослям необходимы соли азота и фосфора. Средняя концентрация этих веществ в водоемах очень мала, и поэтому высокая продуктивность фитопланктона возможна лишь при условии постоянного поступления минеральных веществ в верхний слой воды - в зону фотосинтеза. Также к немаловажному фактору следует отнести слабую турбулентность водоема, т.е. слабое течение или отсутствие такового. Следствием этого является чрезмерно бурное развитие фитопланктона (цветение воды), при разложении которого выделяется сероводород или другие токсичные вещества, что в свою очередь приводит к гибели обитателей водоема и делает воду качественно непригодной. Массовое развитие водорослей зависит от количества растворенного кислорода в водоеме и температуры, т.е. от ее повышения, которое происходит во второй половине весны и летом, иногда продолжающегося до первой половины теплой осени [6, с. 24-25; 7, с. 64-65, 8, с. 74-75].

На неблагоприятное состояние водоема указывает высокое присутствие спирогиры и синедры. Данные виды свидетельствуют о подверженности образования тины в водоеме. По данным нашего исследования, в середине лета температура воды повышалась, а вместе с ней увеличивалась численность синедры (Synedra) и спирогиры (Spirogyra) обусловливая образование большого количества органики, приводящей к загрязнению пресных водоемов. Наличие мужоции (Mougeotia) в исследуемом водоеме в летние месяцы также свидетельствует о его загрязнении.

Наличие высокого количества микроорганизмовбиоиндикаторов говорит о перенасыщении воды кислородом. Кислород является окислителем и участвует в процессах гниения. Поступление кислорода из атмосферного воздуха в воду происходит только за счет фотосинтеза водорослей в дневное время. При этом выявленное нами перенаселение водоема фитопланктоном предопределяет острую нехватку кислорода в ночное время, т.е. в ночное время кислород расходуется до минимума $[9$, с. 25-26; 10 , c. 3-4].

Зимой в пробах воды ерика Судомойка было обнаружено большое количество слизи, яйцекладок различных насекомых, органической грязи, что также свидетельствует о загрязнении водоема в зимний период. При органолептическом анализе были получены следующие данные:

- при температуре $20^{\circ} \mathrm{C}$ : вода бесцветная (прозрачность более 30) с землистым запахом, на вкус сладкая с привкусом мела;

- при температуре $60^{\circ} \mathrm{C}$ : вода бесцветная (прозрачность более 30) с землисто-болотным запахом, на вкус сладкая с привкусом мела.

В серию экспериментов, проводимых в период с марта 2017 года по сентябрь 2017 года, входило измерение растворенного кислорода в воде водоема. В июле и сентябре были зафиксированы скачки увеличения концентрации кислорода, что коррелирует с установленным нами фактом увеличения количества водорослей в исследуемый период. При повышенной температуре водорослям комфортно, и они активируют свою жизнедеятельность [11, с. 231-232; 12, c. $9-10 ; 13$, c. $23-24]$.

Выявленные скачки повышения минерализации воды в марте и июле 2017 года (рис. 1) можно объяснить несколькими явными причинами: антропогенным прессингом и рекреационной деятельностью, имевшим место быть в летний период в специально отведенных местах, а также засором дамб по всей территории водоема. Ерик Судомойка перекрыт двумя дамбами, которые находятся в запущенном состоянии и препятствуют течению ерика, что негативно влияет на экологическое состояние водоема.

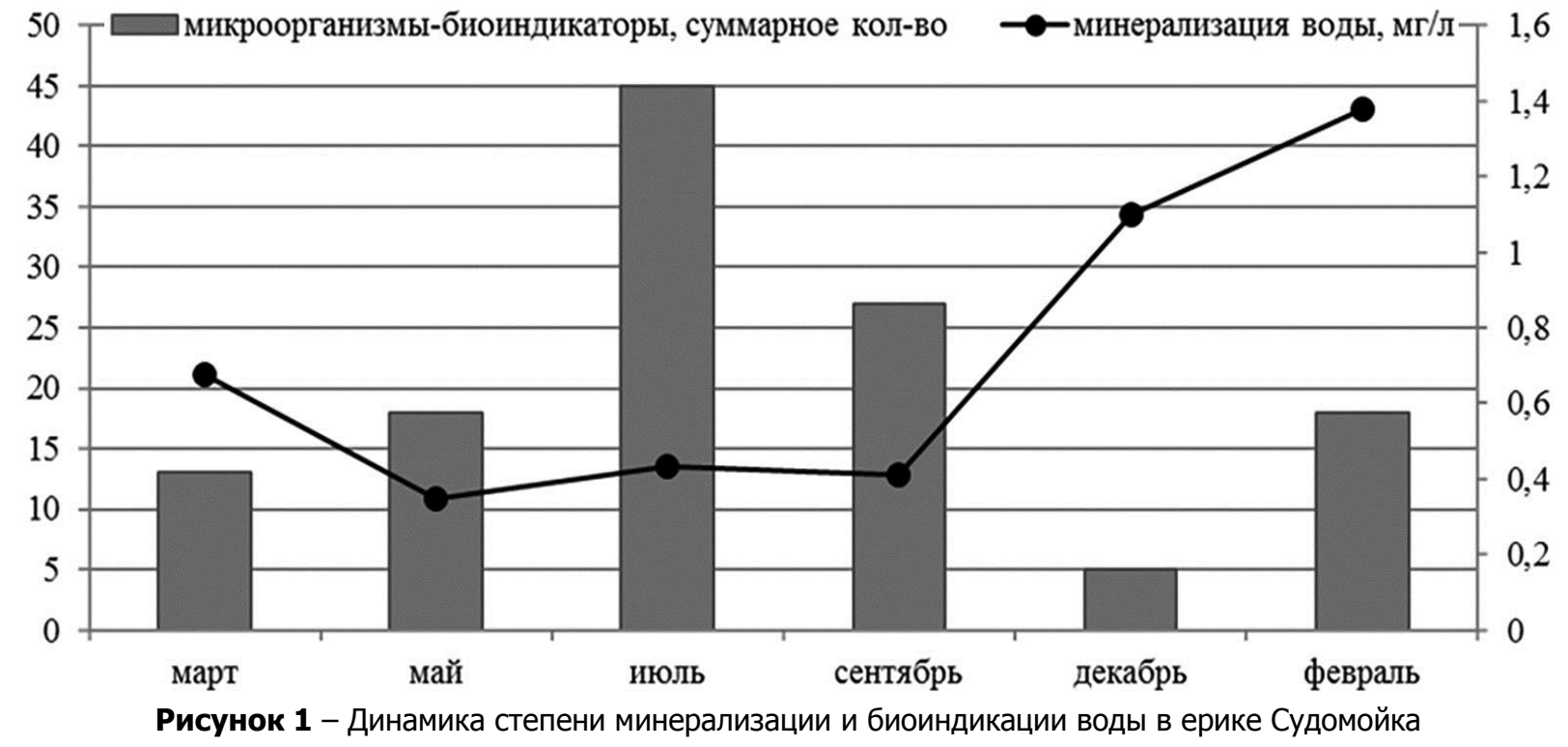

В ходе исследования были также установлены скачки минерализации в зимний период (декабрь 2017 г. и февраль 2018 г.), что не характерно для данного времени года. Такое явление, возможно, обусловлено повышением количества сине-зеленых водорослей, сменивших тип питания ввиду присут-

ствия в водоеме в большом количестве органических веществ.

Рассматривая внешние признаки водоема, необходимо отметить, что береговая линия была загрязнена бытовыми отходами, преимущественно в зимний период, что, в свою очередь, усугубляло имею- 
щееся негативное антропогенное вмешательство в экосистему водоема $[14$, с. $69 ; 15$, с. $14-15]$.

\section{Выводы}

Ерик Судомойка относится к транзиторным водотокам Волго-Ахтубинской поймы, постоянно подвергающимся антропогенному прессингу, т.к. находится вблизи населенных пунктов. Качество воды в ерике Судомойка неудовлетворительное, ерик классифицируется как слабозагрязненный водоем.

Экологическое состояние ерика Судомойки обусловливает экологическое состояние всего природного комплекса Волго-Ахтубинской поймы.

Принадлежность ерика Судомойка к уникальному водному объекту Волгоградской области предопределяет не только проведение мониторинга в непосредственной близости к населенным пунктам г. Краснослободска, но и необходимость организации мониторинговых мероприятий в дополнительных точках, а именно в истоке и устье ерика.

\section{Список литературы:}

1. Вершинина С.А., Маковкина Л.Н. Водные объекты Волго-Ахтубинской поймы // Грани познания. 2015. № 4 (38). С. 20-24.

2. Брызгалина Е.С., Филиппов О.В., Кочеткова А.И., Баранова М.С. Экологическая оценка состояния водных объектов Волго-Ахтубинской поймы в условиях зимнего периода 2014-2015 гг. // Грани познания. 2015. № 4 (38). С. 104-113.

3. Онищенко Г.Г. Состояние питьевого водоснабжения в Российской Федерации: проблемы и пути решения // Гигиена и санитария. 2007. № 1. С. 10 13.

4. Коломин Ю.М. Экологический мониторинг состояния водоемов Северо-Казахстанской области и использование их биоресурсов // Экологический мониторинг и биоразнообразие: сб. материалов IV междунар. науч.-практ. конф. Ишим, 2012. С. 110 113.

5. Жумадилова Ж.Ш., Сапаргалиева Г.М., Изимбет А.П. и др. Культивирование микроводоросли с целью получения биомассы в лабораторных услови- ях // Международный журнал прикладных и фундаментальных исследований. 2015. № 10-5. С. 838-839.

6. Алешня В.В., Журавлев П.В., Головина С.В. и др. Значение индикаторных микроорганизмов при оценке микробного риска в возникновении эпидемической опасности при питьевом водопользовании // Гигиена и санитария. 2008. № 2. С. 23-27.

7. Леванова Г.Ф., Мазепа В.Н., Кашников С.Ю. Экспресс-метод биотестирования воды в полевых условиях // Гигиена и санитария. 2004. № 1. С. 64-66.

8. Бойцов А.Г., Ластовка О.Н., Кашкарова Г.П., Благова О.Е. Оценка качества воды по биологическим показателям: пути совершенствования // Гигиена и санитария. 2005. № 1. С. 74-77.

9. Базилевич Н.И., Родин Л.Е. Географические закономерности продуктивности и круговорота химических элементов в основных типах растительности Земли // Общие теоретические проблемы биологической продуктивности. Л.: Наука, 1969. С. 24-33.

10. Будаговский А.И. Ресурсы почвенных вод и водообеспеченность растительного покрова // Водные ресурсы. 1985. № 4. С. 3-13.

11. Петров Б.И., Денисова С.А., Леснов А.Е. Фазовые равновесия и распределение элементов в системах вода - антипирин - органическая кислота // Известия Алт. гос. ун-та. 2003. № 3 (29). С. 230-236.

12. Курамшина Н.Г., Курамшин Э.М., Лапиков В.В. Комплексный экологический мониторинг водных экосистем в условиях техногенеза // Экологические системы и приборы. 2004. № 8. С. 9-11.

13. Алешня В.В., Журавлев П.В., Головина С.В. и др. Значение индикаторных микроорганизмов при оценке микробного риска в возникновении эпидемической опасности при питьевом водопользовании // Гигиена и санитария. 2008. № 2. С. 23-27.

14. Позин С.Г. О некоторых подходах к запрету купания в водоемах по результатам микробиологического анализа воды // Медицинские новости. 2005. № 9. С. 69-70.

15. Рахманин Ю.А. Приоритетные направления и критерии оценки загрязнения окружающей среды // Гигиена и санитария. 2003. № 6. С. 14-16.

\title{
ENVIRONMENTAL MONITORING OF THE SUDOMOYKA RIVER IN THE VOLGO-AHTUBINSKY FLOODPLAIN
}

(C) 2018

\author{
German Nadezhda Valerievna, candidate of biological sciences, \\ associate professor of Ecology and Nature Management Department \\ Babicheva Alina Valentinovna, student of Natural Sciences Institute \\ Manaenkov Igor Viktorovich, candidate of biological sciences, \\ associate professor of Ecology and Nature Management Department \\ Volgograd State University (Volgograd, Russian Federation) \\ Sevriukova Galina Aleksandrovna, doctor of biological sciences, associate professor, \\ professor of Industrial Ecology and Life Safety Department \\ Volgograd State Technical University (Volgograd, Russian Federation)
}

\footnotetext{
Abstract. The paper is devoted to ecological monitoring and system analysis of the Volgograd Region (the Sudomoyka Erik) reservoir. Environmental monitoring was conducted from March 2017 to February 2018. The set of studies included: determination of water organoleptic characteristics, the amount of dissolved oxygen in the water, $\mathrm{pH}$ value, a dry residue and bioindication. The authors note microorganism number increase: Synedra, Spirogyra, Mougeotia in July and September 2017 and in February 2018 which are biological indicators of water quality. The presence of a high number of microorganisms-bioindicators testifies to the supersaturation of water with oxygen and the formation of organic substances. The authors found an increase in salinity of water in March, July and December 2017, February 2018. In winter in the water of the Sudomoyka Erik the authors found large amounts of mucus, eggs of various insects, organic dirt, which indicates the water pollution in the winter. Water quality in the Sudomoyka
} 
Герман Н.В., Бабичева А.В., Манаенков И.В., Севрюкова Г.А. 03.02.00 - общая биология Экологический мониторинг ерика Судомойка Волго-Ахтубинской поймы...

Erik is unsatisfactory, the Eric is classified as a slightly polluted body of water. The Sudomoyka Erik cannot be used for domestic purposes by residents of nearby settlements and is unfavorable for swimming in summer. The ecological state of the Sudomoyka Erik determines the ecological state of the entire natural complex of the VolgaAhtubinsky floodplain.

Keywords: Volgograd Region; Volgo-Ahtubinsky floodplain; Sudomoyka Erik; natural park; ecological monitoring; system analysis; pollution; water salinity; hydrogen index; bioindication; Synedra; Spirogyra; Mougeotia.

УДК $574(630 * 5)$

Статья поступила в редакцию 09.06.2018

\title{
ОПЫТ БИОИНДИКАЦИИ СОВРЕМЕННЫХ ЛЕСОВ В ТАТАРСТАНЕ
}

(C) 2018

Глушко Сергей Геннадьевич, кандидат сельскохозяйственных наук, доцент кафедры таксации и экономики лесной отрасли

Казанский государственный аграрный университет (2. Казань, Российская Федерация)

Прохоренко Нина Борисовна, кандидат биологических наук, доцент кафедры ботаники и физиологии растений

Казанский (Приволжский) федеральный университет (2. Казань, Российская Федераџия)

\begin{abstract}
Аннотащия. В различных регионах антропогенное воздействие привело к гибели лесов и уничтожению значительной их части. С разрушением лесной растительности на большой площади происходит формирование новых природных условий. В складывающейся ситуации способы оценки лесов и лесорастительных условий нуждаются в корректировке и дальнейшем совершенствовании. Использование данных учёта доминантных, эдификаторных, дифференциальных видов растений позволяет дать оценку лесорастительным условиям преимущественно на определенных этапах развития сообщества. Результаты подобных исследований могут быть использованы для целей краткосрочного лесного планирования. В целях долгосрочного прогноза динамики лесорастительных условий предлагается использовать материалы исследований жизненной стратегии лесных растений и лесных сообществ в целом. Комплексная характеристика поведения растений или их стратегия жизни отражает процесс адаптации растительности к формирующимся лесорастительным условиям. На примере лесов Республики Татарстан рассмотрена возможность определения природных условий по особенностям жизненной стратегии отдельных лесообразующих пород. Тип жизненной стратегии древесных пород выявлялся по показателям хода роста, а также длительности жизни. Сделан вывод о том, что основные лесообразующие породы в Татарстане, адаптируясь к формирующимся условиям, проявляют признаки пионерного поведения или эксплерентной стратегии.
\end{abstract}

Ключевые слова: лесная биота; лесорастительные условия; устойчивость лесов; стратегия жизни растений; адаптация; лесоводственные свойства пород.

\section{Введение}

Лесная биота составляет значительную часть биосферы и активно участвует в средообразовательных процессах, в том числе в формировании лесорастительных условий. Массовое сведение лесов и уничтожение коренной биоты существенно изменило процессы формирования природной среды, отразилось на лесообразовательных процессах, а также повлияло на состояние сохранившихся лесных биогеосистем - региональных фрагментов биосферы. Республика Татарстан характеризуется высокой степенью хозяйственного освоения земель, низким уровнем лесистости (около 17\%) и повсеместным замещением остатков условно-коренных лесов производной растительностью [1].

В большинстве своем основные нормативные документы лесного хозяйства и лесоводственная литература характеризуют преимущественно коренные леса, в них слабо отражено их современное состояние и принадлежность определенному типу леса. Проблемы типологии современных лесов, индикации лесорастительных условий и оценки антропогенных тенденций лесообразовательного процесса имеют практическое значение и заслуживают детального исследования.

В данной связи задачу исследований - индикация состояния лесов региона по характеру жизненной стратегии пород-лесообразователей в современных условиях хозяйствования - считаем достаточно актуальной.

\section{Объекты, материалы и методы исследований}

Участвуя (2011-2016 гг.) в лесоустройстве Пригородного, Лаишевского, Ислейтарского, Заинского и Зеленодольского лесничеств Татарстана, авторами были заложены около 20 пробных площадей размером 0,25-1 га. Маршрутно-рекогносцировочные обследования лесов и закладка пробных площадей выполнялись в соответствии с программой и методикой биогеоценологических исследований [2]. Работы на пробных площадях велись с использованием стандартных указаний. Жизненная стратегия рассматривается нами в понимании Л.Г. Раменского [3] и T.А. Работнова [4]. Выделение типа жизненной стратегии древесных пород проводилось по показателям их хода роста, длительности жизни и бонитета.

\section{Результаты исследований и их обсуждение}

В настоящее время современные леса необходимо привести в известность и, в частности, установить их лесотипологическую принадлежность. Лесотипологическое направление в биогеоценологии с оценкой лесов по облику самой растительности используется только в целях краткосрочного планирования, не отвечая потребностям планирования долгосрочного. В 